\title{
Yoga for Patients with Early Breast Cancer and its Impact on Quality of Life - a Randomized Controlled Trial
}

\section{Der Einfluss von Yoga auf die Lebensqualität bei Brustkrebspatientinnen - eine randomisiert-kontrollierte Studie}

Authors

Affiliations
F. Siedentopf ${ }^{1}$, I. Utz-Billing ${ }^{2}$, S. Gairing ${ }^{2}$, W. Schoenegg ${ }^{1}$, H. Kentenich ${ }^{3}$, I. Kollak ${ }^{4}$

${ }^{1}$ Klinik für Gynäkologie und Geburtshilfe, Martin-Luther-Krankenhaus, Berlin

${ }^{2}$ Frauenklinik DRK-Kliniken Berlin, Standort Westend, Berlin

${ }^{3}$ Fertility Center, Berlin

${ }^{4}$ Alice-Salomon-Fachhochschule, Berlin

\section{Key words}

- breast cancer

- yoga

- oncological care

- quality of life

Schlüsselwörter

- Brustkrebs

- Yoga

onkologische Versorgung

- Lebensqualität

\section{received 10.3.2013 \\ revised 15.3.2013 \\ accepted 15.3.2013}

Bibliography

DOI http://dx.doi.org/

10.1055/s-0032-1328438

Geburtsh Frauenheilk 2013; 73 :

311-317 @ Georg Thieme

Verlag KG Stuttgart · New York ISSN 0016-5751

\section{Correspondence}

\section{Dr. Friederike Siedentopf}

Martin-Luther-Krankenhaus

Klinik für Gynäkologie und

Geburtshilfe

Caspar-Theyß-Straße 27-31

14193 Berlin

friederike.siedentopf@gmx.de

\section{Abstract \\ $\nabla$}

The aim of this prospective, randomized, controlled trial was to investigate the impact of yoga on newly diagnosed patients with early breast cancer in the immediate postoperative phase. 93 women newly diagnosed with early breast cancer were randomized into an intervention group (IG) and a control group (waiting group, WG). The IG started yoga immediately after the operation. The WG started yoga 5 weeks after surgery. Both groups attended yoga classes twice weekly for 5 weeks. Quality of life (QoL) was evaluated using the EORTC QLQ-C30 and EORTC QLQ-BR23 questionnaires before the intervention, immediately after the operation and after 3 months. After 3 months the patients were asked whether yoga improved their physical activity and whether they wished to continue with yoga. The overall QoL $(\mathrm{p}=0.002)$ and the functional status $(\mathrm{p}=0.005)$ increased significantly in the IG, while physical symptoms decreased over time in both groups. $86 \%$ of patients in the IG and only $59 \%$ of patients in the WG $(p=0.04)$ confirmed a positive change in their physical activity through yoga. More women in the IG intended to continue with yoga $(p=0.03)$. Early initiation of yoga as a supportive treatment in cancer had a positive impact on QoL. Teaching yoga allowed patients to practice yoga by themselves, enhanced the patients' QoL and was found to improve physical activity.

\section{Introduction}

$\nabla$

Breast cancer is the most common malignancy in women worldwide. It accounts for $14 \%$ of all cancer diagnoses in Europe [1]. In the industrialized countries of the northern hemisphere, between

\section{Zusammenfassung \\ $\nabla$}

Das Ziel dieser prospektiven randomisierten und kontrollierten Studie war es, den Einfluss von Yoga bei Brustkrebspatientinnen in der früh-postoperativen Phase zu untersuchen. 93 Frauen mit neu diagnostiziertem Mammakarzinom wurden in eine Interventionsgruppe (IG) und eine Kontrollgruppe (Wartegruppe, WG) randomisiert. Die IG begann sofort nach der Operation mit Yoga. Die WG startete 5 Wochen später. Für beide Gruppen erfolgten die Yogaübungen $2 \times$ wöchentlich. Die Lebensqualität (QoL) der Patientinnen wurde mithilfe des EORTC QLQ-C30 und des EORTC QLQ-BR23 unmittelbar vor und nach der Intervention sowie nach 3 Monaten erfasst. Nach 3 Monaten wurden die Patientinnen zusätzlich zum Einfluss von Yoga auf ihre körperliche Aktivität sowie zu ihrem Wunsch, Yoga weiterhin zu praktizieren, befragt. Die globale $\mathrm{QoL}(\mathrm{p}=0,0002)$ und der funktionelle Status ( $p=0,005)$ verbesserten sich in der IG signifikant, während die körperlichen Symptome im Verlauf in beiden Gruppen nachließen. 86\% der Patientinnen in der IG und nur 59\% der Patientinnen in der WG $(p=0,04)$ bestätigten einen positiven Einfluss des Yoga auf ihre körperliche Aktivität. Mehr Frauen der IG äußerten die Intention, Yoga weiterhin zu praktizieren $(p=0,03)$. Der frühe Beginn von Yogatraining als supportive Maßnahme in der Krebstherapie beeinflusst die QoL positiv. Yoga kann von den Frauen selbstständig praktiziert werden, was ihre Autonomie unterstützt und die körperliche Aktivität verbessert.

one in eight and one in ten women will be diagnosed with breast cancer in their lifetime $[2,3]$. Due to the enormous advances in adjuvant and palliative treatment, it has, in many cases, become a controllable chronic disease [4]. 


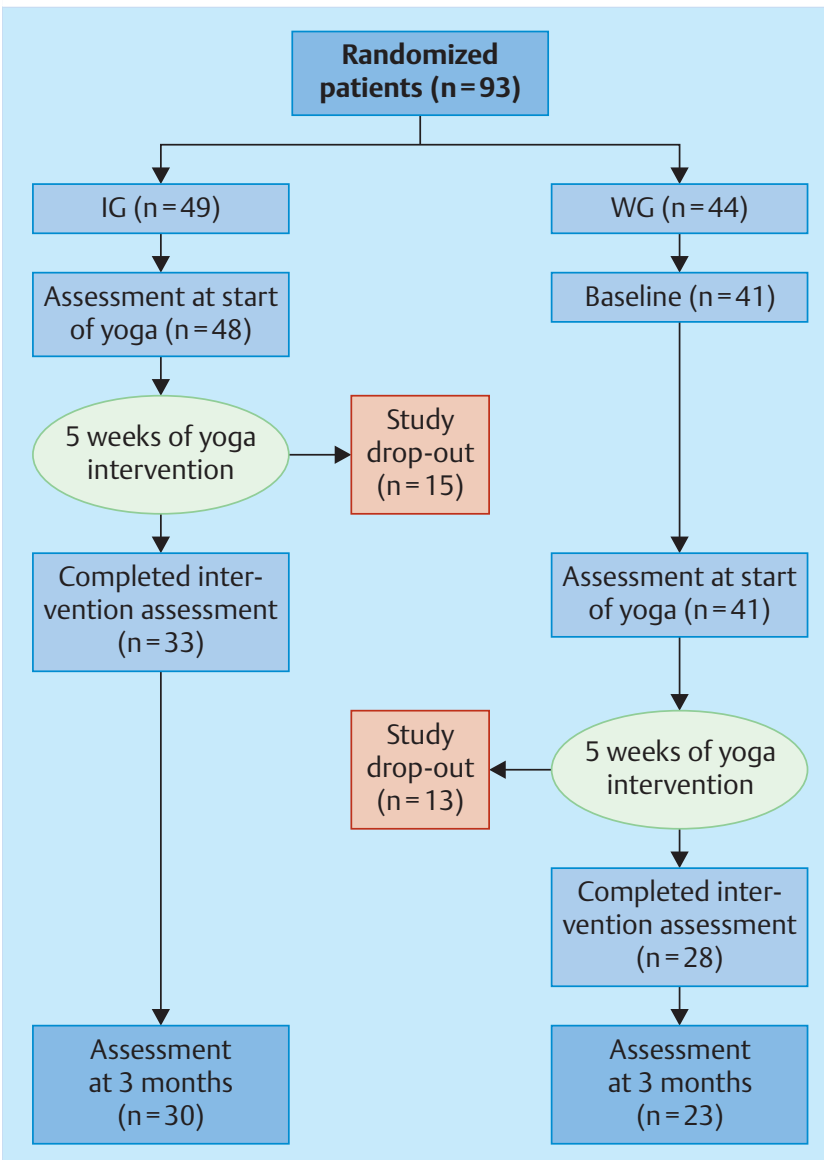

Fig. 1 Flow chart. breast cancer showed a cognitive improvement after participating in yoga programs $[22,23]$. They reported less fatigue when undergoing breast cancer treatment [24-26].

Studies of yoga programs for breast cancer patients found improvements in emotional outcomes and in quality of life $[23,25$, $27,28]$. Anxiety and depression was reduced with yoga interventions compared with supportive therapy following surgery, radiation therapy and chemotherapy [18,29]. Several authors have described an increase in positive affect and a decrease in negative affect in patients with breast cancer who participated in yoga programs $[22,25]$.

Women who were prescribed a 6-week daily yoga program reported improved confidence in social settings relative to controls who had only a brief supportive therapy [22]. Moadel et al. described that participants in a yoga group did not report a significant change in social well-being but the 12-week waiting-list control group noted a significant decrease in support [30].

The aim of our study was to test the hypothesis that newly diagnosed patients with early breast cancer could benefit from yoga in the early postoperative period. This benefit would be expressed primarily by a higher QoL and secondarily by an improvement in physical activity. Furthermore, we hypothesized that QoL is influenced by sociodemographic factors and the type of surgery.

\section{Material and Methods}

The study was approved by the Ethics Committee of the Humboldt University of Berlin. It was conducted at the breast center of DRK Kliniken Westend, Berlin, Germany. Patients were allocated on the ward after admission before their first operation for early breast cancer.

Initially, 93 patients were randomized into an intervention group (IG) and a control group (waiting group, WG). The IG started yoga immediately after the operation. The WG started yoga 5 weeks after surgery. Both groups attended yoga classes twice weekly for 5 weeks. For various reasons 17 patients dropped out in the IG, and 13 dropped out in the WG. The average number of attended yoga classes was 7.62 (SD \pm 3.78 ) in the IG and 7.25 (SD $\pm 4.21)$ in the WG with a range of $0-11$ in both groups $(p=0.89$, Mann-Whitney U-test). No statistical difference was found in the numbers attending classes.

Various reasons were cited for canceling classes, but most patients gave no reason ( 7 women in the IG, 8 women in the WG). The second most frequently cited reason was ongoing adjuvant treatment. No difference was found for both groups $(p=0.50$, likelihood ratio test).

After randomization, 2 patients withdrew their consent and 2 patients were excluded when the inclusion criteria were reassessed. Patient flow is shown in $\bullet$ Fig. 1.

The study cohort consisted of patients with breast cancer who underwent surgery (mastectomy, breast-conserving therapy (BCT), sentinel node biopsy (SLN) or axillary lymph node dissection (ALND). Inclusion criteria were "being able to attend 10 yoga classes over a period of 14 weeks" and "being able to start yoga two to three days after surgery" (IG). All patients who underwent axillary operations had either SLN or ALND. Patients also had to be able to start yoga classes 5 weeks after surgery (WG). The Karnofsky Index was $>70 \%$.

Patients who did not undergo surgery or who underwent procedures other than those listed above, patients with distant metas- 
tases, patients who already regularly attended yoga classes, patients with limited German language skills, patients with alcohol and illicit drug abuse and psychotic disorders were all excluded from the study.

\section{Sample size calculation}

Sample size calculation was performed using G*Power3.1. The estimated number of patients needed to assume a large effect in the study sample (effect size $\mathrm{d}=0.8$ ) was 35 to 37 persons per group, depending on the statistical test used. Because of the expected dropout rate in a longitudinal trial, a larger number of participants were randomized to each group.

To evaluate quality of life (QoL), the German version of the European Organization of Research and Treatment of Cancer QoL questionnaire EORTC QLQ-C30 and its breast-cancer-specific module EORTC QLQ-BR23 were administered at baseline, after the intervention and 3 months after the intervention. These are self-reported questionnaires with a good reliability, validity and sensitivity to change. Validation studies have been completed [31,32]. The EORTC QLQ-C30 includes functional and symptom scales, a QoL scale, and six single items. All scales and single-item measures range in score from 0 to 100 . A high score for a functional scale represents a high level of functioning, a high score for the global QoL represents a high QoL, but a high score for a symptom scale represents a high level of symptoms [31]. The EORTC QLQ-BR23 questionnaire assesses areas related to treatment modalities. It comprises 23 questions and also assesses specific aspects of the QoL in breast cancer patients [33]. Responses are rated on four-point Likert scales.

After 3 months the patients were additionally asked whether practicing yoga had improved their subjective level of physical activity (Did yoga improve the way you move?) and whether they wished to continue yoga after the study (Do you intend to continue yoga classes after the study?).

The study was designed as a randomized, prospective, controlled trial in accordance with the CONSORT guidelines. Written informed consent was obtained from each study participant before randomization. Sealed envelopes were used to individually randomize patients into one of two groups (IG and WG) using a lottery randomization process. With this design we hoped to improve recruitment and acceptance of the study by the patients. Participants completed the questionnaires at baseline (prior to intervention), after yoga classes and 3 months after ending the classes. The WG received no additional interventions beyond adjuvant breast cancer therapy and routine healthcare.

Classes were held in a gym in the hospital and the program was especially created for breast cancer patients [34]. Yoga classes were held twice a week with each class lasting around 75 minutes - not a single yoga class was cancelled during the period of yoga intervention (June 2008 until November 2009). Each participant was asked to attend ten classes over a period of approximately five weeks. Classes were conducted by two certified yoga teachers, one demonstrating the asana together with variations tailored to the needs of patients recovering from surgery, the other teacher assisting the participants with props and finding individual variations of the asana shown. The term "asana" (Sanskrit for "sitting down") refers to the sitting body position in which yoga is practiced. The teachers were trained gitananda and vini yoga teachers who agreed to a defined set of asana (see $\bullet$ Table 1 ) and teaching style. The teachers were careful to ensure that participants performed each exercise according to their own optimal degree of intensity.
Table 1 Synopsis of yoga asana used in yoga classes [34].

\begin{tabular}{|c|c|}
\hline Steps for each yoga class & Yoga postures (asana) \\
\hline $\begin{array}{l}\text { Supine postures: initial posture } \\
\text { to "ground" the patient }\end{array}$ & $\begin{array}{l}\text { Shanti asana posture (Shavasana) } \\
\text { Dorsal tree posture (Vrikshasana) } \\
\text { Hip-joint rotations } \\
\text { (Pada Sanchalanasana) } \\
\text { Knees to chest (Apanasana) }\end{array}$ \\
\hline $\begin{array}{l}\text { Pranayama postures to promote } \\
\text { stretching and breathing }\end{array}$ & $\begin{array}{l}\text { Breathing and moving (Yoga Mudra) } \\
\text { Camel posture (Ushtrasana) } \\
\text { Tiger breathing (Chakravakasana) }\end{array}$ \\
\hline $\begin{array}{l}\text { Postures for the neck, shoulders, } \\
\text { and arms for the relief of tension }\end{array}$ & $\begin{array}{l}\text { Arm and head coordination (Skandha } \\
\text { Chakra) } \\
\text { Head rotations (Greeva Chakra) } \\
\text { Head Bows (Greeva Sanchalana) }\end{array}$ \\
\hline $\begin{array}{l}\text { Eye exercises: alternate tighten- } \\
\text { ing and relaxing of eye muscles }\end{array}$ & $\begin{array}{l}\text { Focus near and far (Nasikagra Drishti) } \\
\text { The lying eight } \\
\text { Cupping and blinking }\end{array}$ \\
\hline $\begin{array}{l}\text { Standing postures: encourage } \\
\text { patients to "stand tall" as before }\end{array}$ & $\begin{array}{l}\text { Hero } 1 \text { and } 2 \text { (Virabhadrasana) } \\
\text { Knee and hip rotations (Janu Chakra) } \\
\text { Stargazer (Hasta Utthanasana) } \\
\text { Triangle in motion (Utthita Trikonasana) }\end{array}$ \\
\hline $\begin{array}{l}\text { More supine postures: } \\
\text { lying on the mat }\end{array}$ & $\begin{array}{l}\text { Boat posture (Paripurna Navasana) } \\
\text { Shoulder bridge (Dvipada Pitham) } \\
\text { Knees to chest (Apanasana) }\end{array}$ \\
\hline $\begin{array}{l}\text { Relaxing postures to feel } \\
\text { the effects of yoga }\end{array}$ & $\begin{array}{l}\text { Kaya Kriya } \\
\text { Yoga Nidra }\end{array}$ \\
\hline $\begin{array}{l}\text { Energizing postures } \\
\text { to end yoga practice }\end{array}$ & $\begin{array}{l}\text { Alternate nostril breathing } \\
\text { (Nadi Shodana) } \\
\text { Chanting } \\
\text { Seated posture (Virasana/Sukhasana) }\end{array}$ \\
\hline
\end{tabular}

Each lesson started with lying postures and the gradual mobilization of arms and legs to encourage flexibility and strength. Various breathing exercises followed to allow participants to feel their chest wall expanding. During the dynamic part of the exercises, a range of standing and sitting positions were shown. These postures aimed to enhance mobility of the arms and shoulders and strengthen the legs and feet as well as improving balance. Eye exercises were an important element of the session to help alleviate the vision problems that can be caused by chemotherapy, although more research is needed to validate these effects.

At the end of the class, participants were led through a series of concentration exercises to help them relax and become aware of the effects of the yoga exercises. The yoga class encompassed a large variety of movements, all of which were easily doable in their modified versions. The modifications were created to meet post-surgical needs and to help during the period following therapy when the women were less flexible.

\section{Outcome measures}

The primary outcome measure was the QoL of the patients before, immediately after, and three months after the intervention. The influence of yoga on physical activity served as a secondary outcome measure.

\section{Statistical analysis}

Scoring of the questionnaires was done according to the guidelines given in the test manuals. A missing data analysis was performed and all variables were analyzed for normality. Means and standard deviations for interval data were obtained, and independent two-sample t-tests were performed for normally distributed data. Mann-Whitney U-test was used for abnormally 
distributed data. The $\mathrm{X}^{2}$ test was used to assess the significance of differences in proportions for nominal and ordinal variables. The likelihood ratio test was used if the conditions for chi-square testing were not fulfilled. Friedman test was used for nonparametric measures and one-way repeated measures analysis of variance (ANOVA) for longitudinal measures in dependent samples. Twosided p-values $<0.05$ were considered statistically significant. Data analysis was done using SPSS version 17.0 (Chicago, IL, USA).

\section{Results}

\section{Baseline characteristics}

Sociodemographic and clinical sample characteristics are shown in 0 Table 2. Due to missing values, some of the variables do not sum to $n=49$ (intervention group, IG), $n=44$ (waiting group, WG) or $n=93$ (total sample). Mean patient age was 55.82 (SD \pm 10.72 , R 37-78) for the IG and 58.41 (SD $\pm 9.91,40-84$ ) for the WG $(\mathrm{p}=0.23$, independent samples t-test). All sociodemographic parameters were comparable between the groups.

Due to the high number of participants who dropped out for various reasons (16 in the IG, 16 in the WG; $\bullet$ Fig. 1) only 31 women completed the intervention in the IG and 28 women in the WG. After 3 months, 30 women of the IG and 23 women of the WG answered the questionnaires.

Over time, the quality of life (QoL) scores changed in both groups. Using the EORTC scales, global QoL and functional status increased while symptoms decreased ( Table 3). Symptoms that improved over time were fatigue, nausea and vomiting, pain, dyspnea, insomnia, appetite loss and other gastrointestinal symptoms. Breast-specific symptoms that became less troublesome over time were systemic therapy side effects, breast and arm symptoms and distress at hair loss.

Women in the IG had a higher overall QoL and functional status after 5 weeks of yoga classes than women in the WG at the same point in time ( 5 weeks after the operation) before the start of yoga classes. The improvement of overall QoL and functional status was only statistically significant in the IG ( $p=0.002$ and $p=0.005$, resp.). Symptoms decreased in the IG and in the WG over a period of 3 months. Patients in the IG had fewer symptoms after 5 weeks of yoga classes. Women in the WG had more symptoms after yoga classes; these symptoms decreased 3 months later. The de-
Table 2 Sample characteristics.

\begin{tabular}{|c|c|c|c|c|}
\hline Parameter & IG n (\%) & WG n (\%) & Total n (\%) & p \\
\hline Nationality & & & & $0.71^{\mathrm{a}}$ \\
\hline - German & $46(96)$ & $36(97)$ & $82(97)$ & \\
\hline other & $2(4)$ & $1(3)$ & $3(3)$ & \\
\hline $\begin{array}{l}\text { Living in } \\
\text { a partnership }\end{array}$ & & & & $0.37^{b}$ \\
\hline yes & $30(64)$ & $27(73)$ & $57(68)$ & \\
\hline no & $17(36)$ & $10(27)$ & $27(32)$ & \\
\hline Marital status & & & & $0.93^{c}$ \\
\hline - unmarried & $13(27)$ & $9(24)$ & $22(24)$ & \\
\hline married & $22(46)$ & $19(51)$ & $41(44)$ & \\
\hline divorced & $7(15)$ & $4(11)$ & $11(12)$ & \\
\hline widowed & $6(12)$ & $5(14)$ & $11(12)$ & \\
\hline Level of education & & & & $0.15^{c}$ \\
\hline D high & $22(51)$ & $22(67)$ & $44(58)$ & \\
\hline - intermediate & $14(33)$ & $9(27)$ & $23(30)$ & \\
\hline - low & $7(16)$ & $2(6)$ & $9(12)$ & \\
\hline Employment status & & & & $0.52^{\mathrm{a}}$ \\
\hline - employed & $32(71)$ & $25(66)$ & $57(70)$ & \\
\hline unemployed & $13(29)$ & $12(33)$ & $25(30)$ & \\
\hline \multicolumn{5}{|l|}{ Type of surgery* } \\
\hline $\mathrm{BCT}$ & $29(62)$ & $24(60)$ & $53(61)$ & \\
\hline mastectomy & $18(38)$ & $16(40)$ & $34(39)$ & \\
\hline S SLN & $37(71)$ & $32(78)$ & $69(74)$ & \\
\hline - ALND & $15(29)$ & $9(22)$ & $24(26)$ & \\
\hline \multicolumn{5}{|l|}{ Adjuvant treatment* } \\
\hline - Chemotherapy & & & & $0.14^{\mathrm{a}}$ \\
\hline byes & $17(53)$ & $7(30)$ & $24(44)$ & \\
\hline$>$ no & $15(47)$ & $16(70)$ & $31(56)$ & \\
\hline - Radiotherapy & & & & $0.65^{\mathrm{b}}$ \\
\hline yes & $23(70)$ & $16(64)$ & $39(67)$ & \\
\hline$>$ no & $10(30)$ & $9(36)$ & $19(33)$ & \\
\hline
\end{tabular}

a Likelihood ratio test

${ }^{\mathrm{b}} \mathrm{X}^{2}$ test

c Mann-Whitney U-test

$\mathrm{M}=$ mean; $\mathrm{R}$ = range; $\mathrm{SD}$ = standard deviation

$\mathrm{IG}$ = intervention group; $\mathrm{WG}$ = waiting group; $\mathrm{BCT}$ = breast-conserving therapy

$\mathrm{SLN}=$ sentinel lymph node biopsy; $\mathrm{ALND}=$ axillary lymph node dissection

* Multiple answers possible

Table 3 EORTC QoL scores

\begin{tabular}{|c|c|c|c|c|c|}
\hline EORTC scales & & M (SD) baseline & M (SD) after yoga classes & M (SD) after 3 months & $\mathbf{P}$ \\
\hline \multirow[t]{4}{*}{ Overall QoL } & IG & $51.33(22.23)$ & $59.11(25.08)$ & $66.95(18.96)$ & $F(2)=12.17$ \\
\hline & & & & & $p=0.002^{a}$ \\
\hline & WG & $52.78(23.35)$ & $57.72(20.53)$ & $70.83(15.59)$ & $F(2)=3.96$ \\
\hline & & & & & $p=0.14^{a}$ \\
\hline \multirow[t]{4}{*}{ Functional scales } & IG & $58.39(18.12)$ & $67.40(18.60)$ & $68.26(15.50)$ & $F(2)=6.67$ \\
\hline & & & & & $p=0.005^{b}$ \\
\hline & WG & $57.48(20.70)$ & $62.32(14.85)$ & $67.37(19.18)$ & $F(2)=0.39$ \\
\hline & & & & & $p=0.69^{b}$ \\
\hline \multirow[t]{4}{*}{ Symptoms } & IG & $29.76(18.10)$ & 26.01 (17.19) & $21.99(10.23)$ & $F(2)=0.98$ \\
\hline & & & & & $p=0.42^{b}$ \\
\hline & WG & $26.51(13.89)$ & $28.15(15.57)$ & $22.83(13.76)$ & $F(2)=7.43$ \\
\hline & & & & & $p=0.01^{b}$ \\
\hline
\end{tabular}

a Friedman test

${ }^{b}$ One-way repeated measures ANOVA

$\mathrm{M}=$ mean; $\mathrm{SD}=$ standard deviation

IG = intervention group; WG = waiting group 


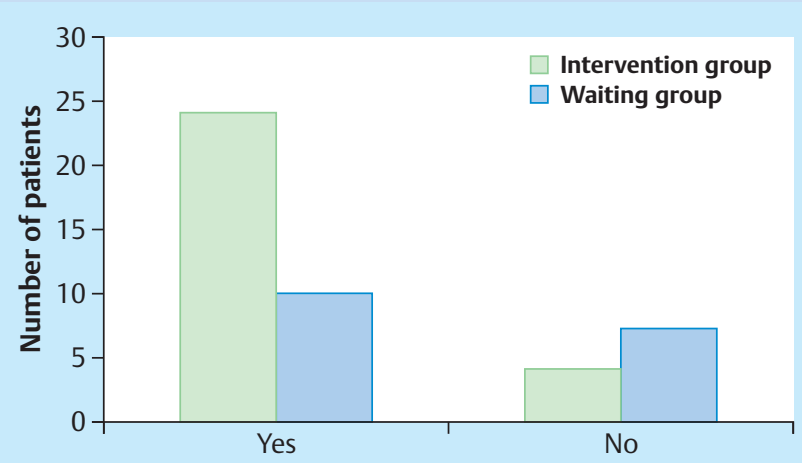

a

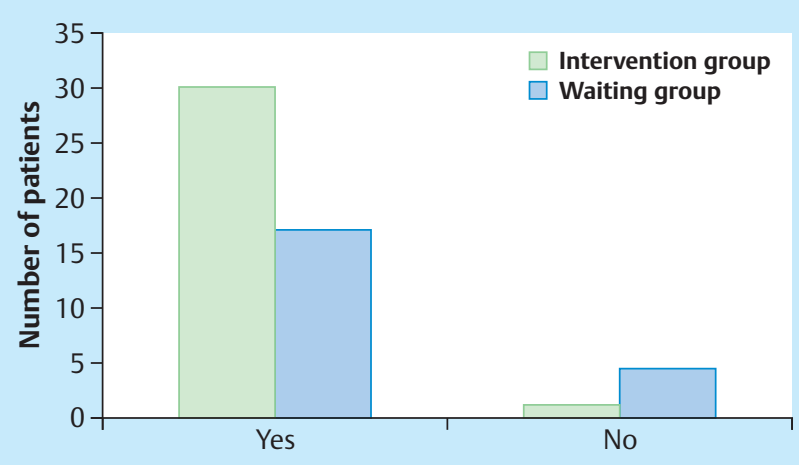

b

Intention to continue with yoga

Fig. $\mathbf{2}$ a and $\mathbf{b}$ a Improvement of physical activity; $\mathbf{b}$ Intention to continue with yoga.

crease in symptoms was statistically significant for the WG $(p=0.01)$. There was no difference in symptoms when women in the IG were compared 5 weeks after surgery and after finishing yoga classes with women in the WG 5 weeks after surgery before the start of yoga.

$86 \%$ (24/28) of the IG affirmed that their physical activity had improved through their participation in the study, compared to only $59 \%(10 / 17)$ of the WG $(\mathrm{p}=0.04)$ ( $\odot$ Fig. $2 \mathrm{a})$. More patients in the
IG (97\%) intended to continue with yoga classes after completing the study ( $\mathrm{p}=0.03$ ) ( Fig. 2 b).

We found that EORTC scores differed significantly depending on the type of surgery performed and on patient age. Functional status after mastectomy $(\mathrm{t}[73]=-2.00 ; \mathrm{p}=0.05)$ was lower than after BCT $(\mathrm{t}[73]=2.20 ; \mathrm{p}=0.03)$. Patients over 60 years of age $(\mathrm{t}$ $[46]=2.09 ; \mathrm{p}=0.04)$ and patients with SLN scored significantly lower on symptom scales than those with ALND ( $\mathrm{t}[45]=-3.01$; $\mathrm{p}=0.00)($ Fig. 3).
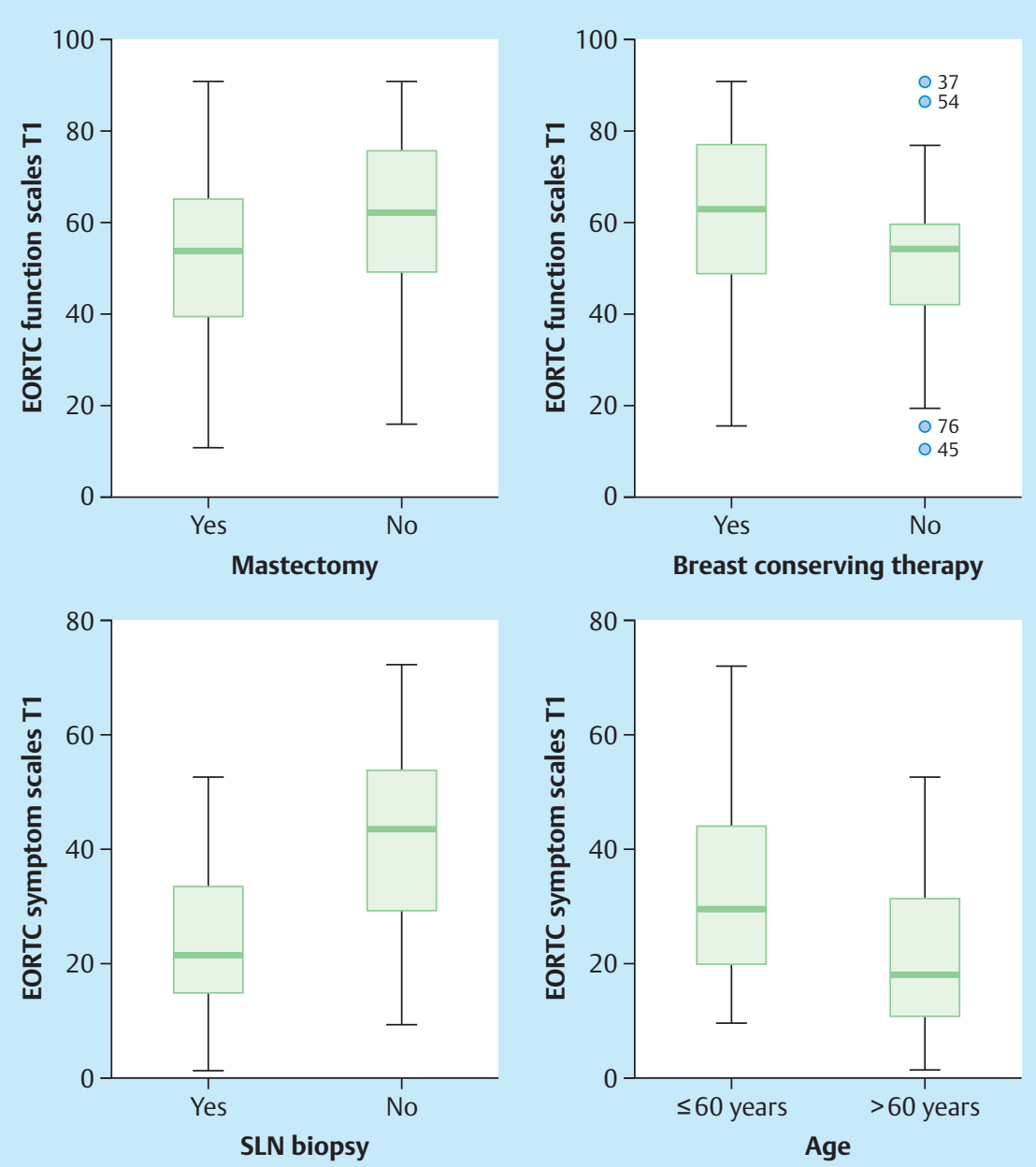

Fig. 3 EORTC functional and symptom scales, depending on the type of surgery and patient age. 


\section{Discussion}

\section{$\nabla$}

In our study we examined the impact of yoga on the quality of life (QoL) of newly diagnosed patients with early breast cancer early after surgery. Our hypothesis was that patients would benefit from the early start of yoga classes.

In both groups the QoL of patients improved over time. In the intervention group (IG) the improvement of the QoL as shown by the overall and functional scales was highly significant $(\mathrm{p}=0.002$ and $\mathrm{p}=0.005$, resp.), whereas in the waiting group (WG) the improvement was much smaller and reached significance only with a decrease of symptoms $(p=0.01)$. Women in the IG had a higher overall QoL and functional status after 5 weeks of yoga than women in the WG at the same time ( 5 weeks after the operation) before the onset of yoga. These results show the advantage of starting yoga classes at an early stage after surgery. The baseline of symptoms was higher in the IG compared with the WG. In the IG, symptoms decreased with yoga. In the WG, symptoms increased during the intervention. This result was most likely due to ongoing adjuvant treatment in the WG. Compared to the results reported by Eyigor et al. [35], the EORTC scores in our sample were lower, but improvements over time and after the intervention were also detectable.

Women in the IG reported significantly more often that they intended to continue with yoga classes and that their physical activity had improved, thus indicating that their overall motivation was higher. We assumed that women need more support immediately after surgery. If additional help is offered at this time, women are more open to continuing with yoga after the intervention. Based on this, it appears helpful to offer yoga classes at an early stage of disease.

The type of surgery performed and patient age also influenced the QoL. Patients who underwent mastectomy had a significantly lower functional status. Older patients ( $>60$ years) and patients with SLN scored significantly lower on the symptom scales than those with ALND. Shortly after surgery, the impact of the type of axillary operation on the other scales was not (yet) measurable; we would need a follow-up investigation of the QoL to clarify this point. We found that breast-conserving therapy (BCT) led to less impairment of functional status, with modern operating techniques probably contributing to this result.

The increased burden of symptoms in younger patients has implications for their care. Like Kwan et al. [36], we assume that early measurement of the QoL during the course of disease measures the distress caused by the diagnosis of cancer and the subsequent operation as a very invasive procedure impacting on a woman's body image and self-confidence. The distress is higher in younger women, so they need special attention and supportive strategies. Our finding is also supported by the data of Høyer et al. [37].

The limitations of the study also have to be mentioned. The patients' acceptance of yoga was very high. At the same time, the study was underpowered and the drop-out rate was high. Sample attrition that occurs between the initial randomization and the outcome measurement is a major problem for the validity of randomized controlled trials. It can result in an incomparability between the intervention group and the controls. For this reason we are aware that the statistical significance of the results could be limited. For some patients, the beginning of adjuvant treatment interfered with the study and made them miss some of the yoga sessions. This was also the main reason for sample attri- tion. We performed a missing data analysis to be certain that both groups were still comparable.

Another important limiting factor is that, with the given study design, we cannot prove that the changes in QoL scales are not simply due to the different times which elapsed since surgery for the IG and the WG. Moreover, funding and personal resources were limited. Nevertheless, the results are promising for the care of breast cancer patients.

\section{Conclusion}

$\nabla$

- A good QoL indicates the patient's ability to cope with the burden of cancer and somatic therapy.

- To support a patient's coping strategies and capacity to heal, encouraging patient self-management is paramount. In our study we assessed the impact of yoga for this.

- Early initiation of yoga classes contributes to improved physical activity and leads to a high motivation to continue training.

\section{Acknowledgements \\ $\nabla$}

This study was made possible through funding from the DRK-Kliniken Berlin, the Alice Salomon University of Applied Sciences and the AOK (Allgemeine Ortskrankenkasse). We are indebted to Dr. Katrin Schüttpelz-Brauns for her support in processing the data.

\section{Conflict of Interest \\ $\nabla$}

F. Siedentopf has received speaker's fees from the companies Roche, GlaxoSmithKline and Dr. Kade-Besins. The other authors declare that they have no financial interests in the study.

\section{References}

1 Ferlay J, Autier P, Boniol $M$ et al. Estimates of the cancer incidence and mortality in Europe in 2006. Ann Oncol 2007; 18: 581-592

2 Gesellschaft epidemiologischer Krebsregister in Deutschland e.V. in Zusammenarbeit mit dem Robert Koch-Institut. Krebs in Deutschland. Häufigkeiten und Trends. Saarbrücken: Eigenverlag; 2006

3 Ries LAG, Eisner MP, Kosary CL. SEER Cancer Statistics Review 19752002. Bethesda: National Cancer Institute; 2005

4 Kümmel S, Kolberg HC, Lüftner D et al. Mammakarzinom 2011 - Neue Aspekte. Geburtsh Frauenheilk 2011; 71: 939-953

5 Ebrahim S. Clinical and public health perspectives and applications of health-related quality of life measurement. Soc Sci Med 1995; 41: 1383-1394

6 Osoba $D$. Lessons learned from measuring health-related quality of life inoncology. J Clin Oncol 1994; 12: 608-616

7 Delgado-Sanz MC, García-Mendizábal MJ, Pollán M et al. Health-related quality of life in Spanish breast cancer patients: a systematic review. Health Qual Life Outcomes 2011; 14: 3

8 Carver CS, Smith RG, Antoni MH et al. Optimistic personality and psychosocial well-being during treatment predict psychosocial well-being among long-term survivors of breast cancer. Health Psychol 2005; 24 : 508-516

9 Fasching PAThiel F, Nicolaisen-Murmann K et al. Association of complementary methods with quality of life and life satisfaction in patients with gynecologic and breast malignancies. Support Care Cancer 2007; 15: 1277-1284

10 Astin JA, Reilly C, Perkins C et al. Breast cancer patients' perspectives on and use of complementary and alternative medicine: a study by the Susan G. Komen Breast Cancer Foundation. J Soc Integr Oncol 2006; 4: 157-169 
11 Fasching PA, Ekici AB, Adamietz BR et al. Breast cancer risk - genes, environment and clinics. Geburtsh Frauenheilk 2011; 71: 1056-1066

12 Eisemann N, Waldmann A, Katalinic A. Epidemiology of breast cancer current figures and trends. Geburtsh Frauenheilk 2013; 73: 130-135

13 Targ EF, Levine EG. The efficacy of a mind-body-spirit group therapy for women with breast cancer: a randomized controlled trial. General Hospital Psychiatry 2002; 24: 238-248

14 Boucher S. Yoga for cancer patients. Yoga J 1999; 146: 42-49; 135-138

15 Ott MJ. Yoga as a clinical intervention. Adv Nurse Pract 2002; 10: 81 $83 ; 90$

16 Rosenbaum E, Gautier H, Fobair P et al. Cancer supportive care, improving the quality of life for cancer patients: a program evaluation report. Support Care Cancer 2004; 12: 293-301

17 Spatz Levine A, BalkJ. Yoga and quality-of-life improvement in patients with breast cancer: a literature review. Int J Yoga Th 2012; 22: 95-99

18 Rao MR, Raghuram N, Nagendra HR et al. Anxiolytic effects of a yoga program in early breast cancer patients undergoing conventional treatment: a randomized controlled trial. Complement Ther Med 2009; $17: 1-8$

19 Duncan MD, Leis A, Taylor-Brown JW. Impact and outcomes of an Iyengar yoga program in a cancer centre. Curr Oncol 2008; 15 (Suppl. 2): s109.es72-s109.es78

20 Van Puymbroeck $M$, Schmid A, Shinew KJ et al. Influence of hatha yoga on physical activity constraints, physical fitness, and body image of breast cancer survivors: a pilot study. Int J Yoga Th 2011; 21: 49-60

21 Raghavendra RM, Nagarathna R, Nagendra HR et al. Effects of an integrated yoga program on chemotherapy-induced nausea and emesis in breast cancer patients. Eur J Cancer Care (Engl) 2007; 16: 462-474

22 Vadiraja HS, Rao MR, Sagarathna $R$ et al. Effects of yoga program on quality of life and affect in early breast cancer patients undergoing adjuvant radiotherapy: a randomized controlled trial. Complement Ther Med 2009; 17: 274-280

23 Culos-Reed SN, Carlson LE, Daroux LM et al. A pilot study of yoga for breast cancer survivors: physical and psychological benefits. Psycho Oncol 2006; 15: 891-897

24 Danhauer SC, Mihalko SL, Russell GB et al. Restorative yoga for women with breast cancer: findings from a randomized pilot study. Psycho Oncol 2009; 18: 360-368

25 Danhauer SC, Tooze JA, Farmer DF et al. Restorative yoga for women with ovarian or breast cancer: findings from a pilot study. J Soc Integr Oncol 2008; 6: 47-58
26 Carson JW, Carson KM, Porter LS et al. Yoga for women with metastatic breast cancer: results from a pilotstudy. J Pain Symptom Manage 2007; 33: $331-341$

27 Moadel SB, Shah J, Wylie-Rosett J et al. Randomized controlled trial of yoga among a multiethnic sample of breast cancer patients: effects on quality of life. J Clin Oncol 2007; 25: 4387-4395

28 Rao RM, Nagendra HR, Raghuram $N$ et al. Influence of yoga on mood states, distress, quality of life and immune outcomes in early stage breast cancer patients undergoing surgery. Int J Yoga 2008; 1: 11-20

29 Banerjee B, Vadiraj HS, Ram A et al. Effects of an integrated yoga program in modulating psychological stress and radiation-induced genotoxic stress in breast cancer patients undergoing radiotherapy. Integr Cancer Ther 2007; 6: 242-250

30 Moadel A, Morgan C, Fatone A et al. Seeking meaning and hope: selfreported spiritual and existential needs among an ethnically-diverse cancer patient population. Psycho Oncol 1999; 8: 378-385

31 Aaronson NK et al. The European Organization for Research and Treatment of Cancer QLQ-C30: a quality-of-life instrument for use in International clinical trials in oncology. J Natl Cancer Inst 1993; 85: $365-$ 376

32 Erickson P. Assessing Health Status and Quality of Life of Cancer Patients: the Use of general Instruments. In: Lipscomb J, Gotay CC, Snyder C, eds. Outcomes Assessment in Cancer. Measures, Methods, and Applications. 1st ed. Cambridge: Cambridge University Press; 2005: 3168

33 Sprangers MA, Groenvold M, Arraras JI et al. The European Organization for Research and Treatment of Cancer breast cancer-specific quality-oflife questionnaire module: first results from a three-country field study. J Clin Oncol 1996; 14: 2756-2768

34 Kollak I, Utz-Billing I. Yoga and Breast Cancer - a Journey to Health and Healing. New York: Demos Medical Publishing; 2011

35 Eyigor S, Karapolat $\mathrm{H}$, Yesil $\mathrm{H}$ et al. Effects of Pilates exercises on functional capacity, flexibility, fatigue, depression and quality of life in female breast cancer patients: a randomized controlled study. Eur J Phys Rehabil Med 2010; 46: 481-487

36 Kwan ML, Ergas IJ, Somkin CP et al. Quality of life among women recently diagnosed with invasive breast cancer: the Pathways Study. Breast Cancer Res Treat 2010; 123: 507-524

37 Høyer $M$, Johansson $B$, Nordin $K$ et al. Health-related quality of life among women with breast cancer - a population-based study. Acta Oncol 2011; 50: 1015-1026 